\title{
LIRISMO E DRAMA EM FLORBELA ESPANCA
}

\author{
Suilei Monteiro Giavara ${ }^{1}$
}

RESUMO: A leitura da obra da poetisa portuguesa Florbela Espanca coloca o leitor diante de uma pessoa poética intensa e oscilante que pode ir desde um tédio infinito até a hipervalorização de sua autoestima. Além disso, sua expressão lírica possui uma intensidade muito próxima do paroxismo, o que pode ser entendido como uma tendência para o drama. Assim, o objetivo deste artigo é verificar a feição lírico-dramática de alguns poemas florbelianos, com enfoque prioritário no tom dialogal que deixam transparecer.

PALAVRAS-CHAVE: Poesia. Florbela Espanca. Literatura portuguesa.

ABSTRACT: The poetry reading of the Portuguese poetess Florbela Espanca puts the reader on an intense and swinging poetic personality that can go from one to the infinite boredom of hyper self-esteem. Moreover, her poetic expression has intensity very close to climax, which can be understood as a tendency for the drama. Thus, the aim of this paper is to verify the feature lyricaldramatic florbelian poems, with primary focus on the dialogic tone that they show.

KEYWO RDS: Poetry. Florbela Espanca. Portuguese literature.

\section{INTRODUÇÃO}

\author{
[‥] \\ Quis Deus fazer-me tua... para nada! \\ - Vãos os meus bracos de crucificada, \\ Inúteis, esses beijos que te dei! \\ Anda!Caminha! Aonde?... Mas por onde?... \\ Se um gesto dos teus a sombra esconde \\ $O$ caminho de estrelas que tracei... \\ (ESPANCA, 1996, p. 220)2
}

O conceito drama era comumente usado para designar poemas criados para serem apresentados, mas a essa definição primeira Emil Staiger (1997, p. 121) acrescenta que nem toda produção dramática deve ser assim denominada porque é passível de adaptação para o palco, mas sim porque é o "espírito dramático", enquanto concepção de mundo, que contém a raiz desse gênero. Assim, é possível afirmar que, mesmo pertencendo a outro gênero, qualquer forma de criação literária pode ser marcada indelevelmente por essa particularidade, advinda da maneira como determinado assunto é tratado ou do ambiente de tensão criado pelo autor.

\footnotetext{
1 Doutoranda - UNESP - Universidade Estadual Paulista. Faculdade de Filosofia, Ciên cias e Letras Departamento de Literatura. Bolsista Fapesp - sugiavara@yahoo.com.br

2 Todas as citações dos poemas de Florb ela Espanca far-se-ão a partir da edição organizada por Maria Lú cia Dal Farra, constante nas referências, por isso, a partir daqui, será colocada somente a página em que se en contram.
} 
O teórico afirma ainda que uma das características responsáveis pelo "estilo de tensão" do drama é o pathos, traduzido do grego como paixão. Tal característica, já apreciada por Aristóteles como um eficiente meio de conduzir o ânimo dos juízes, relaciona-se com a representação ou o despertar das emoções humanas através de um discurso ou de uma obra poética. Por esse motivo, os gregos relacionavam o pathos com as "paixões humanas", responsabilizando-o, portanto, pelo estilo de expressão vincada na exaltação emocional. Assim, "o pathos foi assim, não raras vezes considerado como gênero lírico, até certo ponto com razão, pois que o patético e o lírico transformam-se, com frequência, um no outro [...]” (STAIGER, 1997, p.121)

Assevera Staiger ainda que o tom lírico, ou o "derramar-se lírico" implica um movimento interno, velado, pelo qual o poeta encarcera-se em si mesmo e desvenda a sua interioridade através de uma atitude isolada, somente percebida pelo leitor através da "disposição anímica”, que permite o reconhecimento do conteúdo lírico como uma verdade totalizadora e indiscutível.

Nas palavras dele,

o lírico derrama-se em nosso íntimo como substância fluída, diluindo o que estava firme, levando nossa existência em seu curso. A ação quase não se nota, é interior; pressupõe a simpatia de uma alma igualmente disposta [...] A ação do pathos, ao contrário, não é tão discreta. Pressupõe sempre uma resistência - choque brusco ou simples apatia - que tenta romper com ímpeto. (STAIGER, 1997, p.122)

Desse modo, o discurso movido pelo pathos é marcado por algumas "particularidades estilísticas" que asseguram essa capacidade de entranhar-se tão violentamente na alma do leitor. Dentre essas particularidades, o autor destaca a necessidade de um "ouvinte" que deve ser irmanado, ou comovido, pelos argumentos patéticos, cuja estrutura e teor, despertam a adesão emocional. Portanto, tal tipo de discurso reivindica a presença do "outro", pois somente o "eu” não é bastante na situação comunicativa, instaurando uma perspectiva persuasiva e dramática entre ambos e, consequentemente, estreitando a distância entre o leitor e a obra.

O contato com a poesia de Florbela Espanca deixa entrever não só uma identidade múltipla que, por não caber em si, assume um discurso cuja prodigalidade ultrapassa a fixidez da forma adotada, mas também uma preocupação constante em apresentar ao leitor a identidade dessa persona que ela assume na sua escritura. 
A tendência da poetisa para o drama, seja ele na vida ou na obra, parece ser consensual, basta observar os trabalhos acadêmicos cujo enfoque é a teatralidade de suas produções.

Renata Soares Junqueira, em sua dissertação de mestrado (1992), faz uma análise das máscaras poéticas nos sonetos florbelianos, colocando em evidência os "sortilégios" de que a poetisa lança mão para seduzir o leitor. Depois, em sua tese de doutorado, (2003. p.18) a estudiosa analisa a obra em prosa de Florbela aproximando-a de autores coevos, como Mário Sá-Carneiro, Almada-Negreiros e Fernando Pessoa, ressaltando aspectos de uma teatralidade evidenciada pela adoção de inúmeras máscaras contra a "hostilidade do mundo real".

Armando Nascimento Rosa (1997, p. 240) também associa essa característica à personalidade poética de Florbela ao afirmar que seja na vida, seja na obra, "o síndroma teatral encontra-se mesmo à flor dos escritos e da personalidade de Bela [...]. O teatro, como metáfora da condição humana, e da sua existência pessoal em particular, prevalece como bóia sinalizadora em toda a extensão de sua obra". A justaposição da biografia à obra também contribui para reforçar essa ideia, embora essa faceta florbeliana não resida apenas nos aspectos biográficos, mas também na configuração dramática que ela dá à sua poesia ao apresentar um sem fim de vozes dialogantes, conforme Rosa (1997. p. 240) ressalta no seguinte trecho: "nos sonetos, temos um dialogismo recorrente em que o interlocutor está mudo, ou, para sermos mais precisos, um monologar no qual a voz poética fala para um tu exterior [...]."

\section{UMA POÉTICA QUIMÉRICA...}

A profusão de vozes criadas por Florbela, característica vista por alguns críticos como uma "esquizofrenia lírica" muito amiga da patologia (SEABRA PEREIRA, 1985, p. 33), coloca-nos imediatamente como expectadores a assistir o desenrolar de seu drama interior, que ela faz questão de evidenciar, seja pelo tom confitente de seus versos, seja pelo modo como mostra sua identidade poética. Mais do que isso, é possível supor que a criação desse universo repleto de vozes com os quais o eu poético dialoga é o meio pelo qual a poetisa minimiza a sua solidão.

De fato, nos versos florbelianos essa característica pode se explicitar de duas maneiras mais evidentes: primeiro, através da citação direta do discurso do outro, do qual ela se apropria para compor uma imagem de si e; depois, através das personificações - 
principalmente de elementos da natureza -, usadas para explicitar um interlocutor mudo com o qual dialoga sobre seus anseios.

No primeiro caso, o eu lírico se insere na enunciação de maneira muito aparente, seja através do uso dos dêiticos (minha, me, meu) seja pelo uso da primeira pessoa, conforme indicam os versos seguintes: "Sonho que sou a poetisa eleita," (p. 132); "Tarde da minha terra" (p. 153); "Irmã, Sóror Saudade me chamaste..." (p. 167); "Minha boca tem rosas desmaiadas," (p. 192); "Enche o meu peito, num encanto mago," (p. 209); "E na vida nada tenho e nada sou;" (p. 225).

Graças à presença desse recurso discursivo, os versos florbelianos adquirem uma toada tipicamente autobiográfica, característica que, segundo Jonathan Culler, (1999, p. 789) parece induzir o leitor a "colocar-se na posição" de quem profere as palavras ali escritas ou então a "imaginar uma outra voz dizendo-as". Ao referir-se à lírica, também assegura que ela está particularmente condicionada à noção de que o poema é uma "dramatização de pensamentos e sentimentos de um falante". Portanto, a interpretação do mesmo não pode prescindir da presença de uma assistência para essa voz pronunciada nem do conhecimento da personalidade que a proferiu.

De acordo com suas observações, a relação do receptor com o texto é cooperativa, pois ele tem a onisciência de quem vê de fora ao mesmo tempo em que pode se apropriar do universo interior do poeta. Tal atitude minimiza a distância entre os interlocutores e cria uma empatia entre ambos que, além de propiciar a verossimilhança, também patrocina o tom patético do texto.

De fato, o eu lírico florbeliano procura sempre manter uma relação de cumplicidade com o leitor a fim de "comovê-lo" de que sua dor é legítima, como sugerem os versos de "Hora que passa" (p. 200):

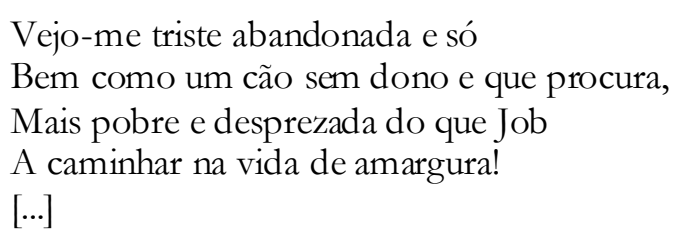

A inserção do falante no discurso, que aqui se dá de modo explícito através do uso da primeira pessoa - "Vejo-me" - em detrimento da terceira, particulariza o episódio à medida que o ego florbeliano passa a ser o ponto sobre o qual esse discurso se estrutura. Assim, tal enfoque atribui autoridade para esse eu lírico falar de si, aumentando o teor patético do sentimento expresso. 
Muitas vezes, a presença do emissor também se dá de modo menos aparente através dos qualificativos escolhidos por ele, pois evidenciam a sua postura diante do objeto foco de sua atenção. No trecho acima, a preferência pelos qualificativos escolhidos para compor uma imagem de si - como um cão sem dono, pobre e desprezada - promove a “compaixão" do leitor, pois realçam sua condição solitária e miserável.

Além disso, convém lembrar que o dialogismo é uma das características peculiares do texto dramático. Mesmo no caso do monólogo, em que há apenas um envolvido nos atos comunicativos, o próprio "eu" posiciona-se como destinatário da mensagem, assumindo um papel reflexivo na estrutura comunicativa. Assim,

O texto dramático [...] caracteriza-se por uma pluriaxialidade das instâncias de enunciação, constituindo os atos lingüísticos produzidos por estas múltiplas instâncias os factores substantivos na construção dos microcontextos e dos macrocontextos dramáticos. (SILVA, 1991, p. 610)

É, portanto, com o desenrolar desses vários eixos discursivos que desenvolve uma determinada situação dramática se instaura e desenvolve, permitindo a ilusão de "realidade" que as peculiaridades na construção do enunciado dramático deixam transparecer.

Também Massaud Moisés (1991, p. 127) afirma que nesse gênero

tudo passa como se, em verdade, tivéssemos de imaginar, no diálogo lido, o diálogo travado entre seres de carne e ossos, apontados no texto como virtualidade à espera do chamado à vida.

Assim, ancorado na verossimilhança, o leitor fantasiosamente reconstrói o contexto e vivifica seres fictícios, instaurando uma suposta realidade.

No plano expressivo, portanto, essa estratégia possibilita a atualização do episódio, uma vez que a reprodução direta oferece vivacidade e naturalidade ao enunciado, além de enriquecê-lo com elementos linguísticos - interjeições, exclamações, reticências, vocativos - que facilitam ao leitor a apreensão dos sentimentos envolvidos no contexto enunciativo. Desse modo, o uso do discurso direto colabora para dinamizar o tom patético de um enunciado à medida que mantém, no discurso citante, as marcas de subjetividade presentes no discurso citado, ou, sugere o enunciado tal qual o proferiu ou deveria proferir o enunciador de origem.

Isso também é enfatizado por Quintiliano (1944, p. 144-5) quando diz que o uso do monólogo e do diálogo no discurso "dá mais peso às paixões" e "faz crível o dito como se a pessoa pensasse interiormente". Portanto, podemos afirmar que auxilia a dar o tom 
patético do texto, porque permite que, na leitura, seja reconstruído o contexto de fala em toda a sua conjuntura.

A poesia florbeliana é um exemplo dessa fartura de vozes que ressoam quer seja o discurso do outro quer seja o seu próprio, criando um povoamento que dá à sua obra uma feição trágica se contraposto ao isolamento de que ela se queixa.

O soneto "Castelã da tristeza" (p. 134) pode ser um bom exemplo de como Florbela, mantendo a essência lírica de sua poesia, cria uma atmosfera dramática através da convivência de uma voz lírica de primeira pessoa com outra em terceira com a qual ela mantém um diálogo:

\section{Castelã da Tristeza}

Altiva e couraçada de desdém, Vivo em meu castelo: a Dor! Passa por ele a luz de todo Amor...

E nunca e meu castelo entrou alguém!

Castelã da Tristeza, vês?... A quem?!...

- E o meu olhar é interrogador Perscruto, ao longe, as sombras do sol-pôr... Chora o silêncio... nada... ninguém vem...

Castelã da Tristeza, porque choras Lendo, toda de branco, um livro de horas, À sombra rendilhada dos vitrais?...

À noite, debruçada p'las ameias, Por que rezas baixinho?... Por que anseias?... Que sonho afagam tuas mãos reais?...

O soneto acima desnuda toda fragilidade desse eu poético à medida que o apresenta ao leitor através da associação entre sua alma e um castelo onde habita a somente a Dor e de onde ela espreita à espera de que alguém possa resgatá-la. O tom interrogativo e os predicativos associados à pessoa poética contribuem para criar um efeito muito próximo do sentimento de angústia que percorre, não somente este texto, mas toda a obra florbeliana.

A descrição dos detalhes que compõem a cena, a presença de uma voz na terceira pessoa e a citação do diálogo em discurso direto - características que fogem um pouco da perspectiva lírica dando-lhe certo pendor para o narrativo - são meios através dos quais a poetisa cria um ambiente "povoado" que ficticiamente suplanta o sentimento do qual é vítima. 
Segundo Vítor Aguiar (SILVA, 1991, p. 227) “a poesia lírica não nasce do anseio ou da necessidade de descrever o real que se estende perante o eu nem de criar sujeitos independentes do eu do poeta lírico", antes a "lírica enraiza-se na revelação e no aprofundamento do próprio eu", ou seja, na exploração da interioridade do poeta. Assim, as descrições não têm a função de compor uma "visão plástica" do mundo exterior, mas sim de suscitar o "estado de alma" desse poeta, conforme pode ser visto no poema citado.

Em “A voz da Tília!” (p. 242), Florbela usa a personificação para proceder à intelecção de sua própria existência. Segue o texto:

Diz-me a tilia a cantar: "Eu sou sincera,

Eu sou isto que vês: o sonho, a graça,

Deu ao meu corpo, o vento quando passa,

Este ar escultural de Bayadera...

E de manhã o sol é uma cratera,

Uma serpente de oiro que me enlaça...

Trago nas mãos a mão da primavera...

E é para mim que em noites de desgraça

Toca o vento Mozart, triste e solene,

E à minha alma vibrante, posta a nu,

Diz a chuva sonetos de Verlaine..."

E, ao ver-me triste, a tília murmurou:

"Já fui um dia poeta como tu...

Ainda hás de ser tilia como eu sou...”

Para Concepción Delgado Corral (1997, p. 139) a natureza na obra florbeliana é "algo mais do que o objecto por que se manifesta amor", é a fonte de onde a poetisa extrai "a maior parte dos símbolos que utiliza" para construir a própria identidade e, na simbologia desses elementos naturais,

as árvores aparecem como símbolo de vida, sobretudo quando florescem, e também, como a montanha (pela sua verticalidade), são elementos de relação entre o mundo terrestre e o mundo superior, neste último sentido, simbolizam o $e u$ no seu desejo de transcendência, em luta entre o ideal e o mundo da terra.

Ousaríamos acrescentar ainda que a escolha de uma espécie hermafrodita que tem autossuficiência para a fecundação pode simbolizar o desejo de autossuficiência artística tão almejado pela poetisa, conforme sugerem os sonetos "Vaidade" (p.132) - "Sonho que sou a poetisa eleita, / Aquela que diz tudo e tudo sabe," -, "Tortura" (p.135) - "Quem me dera encontrar o verso puro, / O verso altivo e forte, estranho e duro," -, "A maior Tortura" 
(p.143) - "Mas a minha tortura inda é maior: / Não ser poeta assim como tu és," - e vários outros que indicam o desejo da expressão poética autêntica.

Não podemos esquecer também o fato de que esse soneto encontra-se em Charneca em Flor, livro em que a capacidade poética de Florbela é mais veementemente explícita através da identificação com os elementos da natureza. Indiretamente, essa identificação ressoa a consciência literária de Florbela, como indicam os versos proféticos finais em que ela é nivelada à condição da tília, "sincera, grácil, formosa como a bayadera", cuja performance é delineada pelo vento, pela sedução do sol e pela chuva.

Sobre essa "atitude dialogante", Benedito Nunes (ano, apud: GUINSBURG, 1993. p.67) afirma que o poeta romântico vê nos objetos a condição de "segunda pessoa o tu diante do Eu - é o nexo de simpatia que o ligará às coisas, num mundo em que tudo pode ser analogicamente compreendido". Assim, mais uma vez, a tília é uma metáfora representativa do próprio eu lírico ou daquilo que esse eu lírico gostaria de ser.

O teor apostrofante, explicitado a partir da terceira estrofe, revela um processo de internalização do eu lírico - culminando na sua fusão com esses elementos da natureza; o que é reiterado pelo pronome possessivo "nosso", através do qual a poetisa compara o seu destino ao da neve: "branca e fria", predicativos que denunciam a neurastenia sugerida pelo título do soneto.

A partir daqui, se mostra o tom dramático reiterado pelo uso das reticências e das exclamações, evidências de uma expressão marcada pela tortura de não poder "gritar ao mundo a sua amargura", necessitando, por isso, recorrer aos elementos da natureza que satisfaçam o seu desejo de transcendência.

\section{CONCLUSÃO}

Da leitura da obra florbeliana uma verdade desponta incontestável: que suas poesias apresentam uma notável personalidade lírica, pelo estilo veemente com que confessa sua dor, pela intensidade do erotismo feminino e pelo tom intimista que imprime aos seus sonetos, afastando-se da fórmula silogística clássica e aproximando-se de um estilo fluído e dialogal, no qual transparecem várias vozes num discurso elíptico, em que os silêncios, preenchidos pelo leitor, são extremamente significativos e responsáveis pela manifestação de certo coloquialismo.

${ }^{3}$ Bayadera é uma dançarina Indiana. 
Mais do que isso, como bem pontua Fábio Mario (2009), os sonetos florbelianos possuem um narcisismo, expresso, não somente pelo fato de Florbela voltar-se para a própria identidade na tentativa de decifrá-la e - ao mesmo tempo - apresentá-la ao leitor, mas também pela "superestima das próprias capacidades e aptidões" e, por último por seus versos serem um espelho no qual o leitor mira a sua própria imagem, "apaixonando-se" por ela ou por aquilo que imagina ser seu próprio "Eu”, (SILVA, 2009, p. 47) e, desse modo, a poesia florbeliana permite ao leitor "purgar" emoções reconhecidamente humanas que nos formam e transformam.

\section{REFERÊNCIAS BIBLIOGRÁFICAS}

CORRAL, C. D. In: LOPES, O. et al. A Planície e o Abismo. 1 ed. Évora: Vega, 1997. p.p. $137-42$.

CULLER, J. Teoria literária: uma introdução. São Paulo: Beca Produções Culturais, 1999.

ESPANCA, F. Poemas. Maria Lúcia Dal Farra (Org). 1. ed. São Paulo: Martins Fontes, 1996.

JUNQUEIRA, R. S. Sob os Sortilégios de Circe: ensaio sobre as máscaras poéticas de Florbela Espanca. Dissertação (Mestrado em Teoria Literária). 1992 Instituto do Estudo da Linguagem, Universidade de Campinas, Campinas, 1992.

. Florbela Espanca: uma estética da teatralidade. São Paulo: Editora Unesp, 2003.

MOISÉS, M. A análise literária. São Paulo: Cultrix, 1991.

NUNES, B. A Visão Romântica. In: GUINSBURG, J. (org.) O Romantismo. 3. ed. São Paulo: Perspectiva, 1993.

QUINTILIANO, M. F. Instituições Oratórias. Tomo 1 e 2, São Paulo: Edições Cultura, 1944. Jerônimo Soares Barbosa (Trad.)

ROSA, A. N. As Máscaras da Florbela Mítica na Dramaturgia Portuguesa. In: LOPES, O. et al. A Planície e o Abismo. 1. ed. Évora: Vega, 1997, p.p. 237-48.

SARAIVA, A. J. \& LOPES, O. História da Literatura Portuguesa. $7^{\mathrm{a}}$ ed. Porto: Martins Fontes, 1973.

SEABRA-PEREIRA, J. C. A águia e o Milhafare (derrota passional e malogro do Eu absoluto na prosa literária de Florbela Espanca: dos contos ao diário). In: Obras Completas de Florbela Espanca. v. 3, Lisboa: Dom Quixote, 1985. p.p 3-35.

SILVA, Fábio Mário da, Da metacrítica à psicanálise: angústia do Eu na poesia de Florbela Espanca. Dissertação (Mestrado em Estudos Lusófonos) 2009. Departamento de 
Linguística e Literaturas, Universidade de Évora, Évora: 2009.

SILVA, V. M. de A. e. Teoria da Literatura. 8. ed.. Coimbra: Almedina, 1991.

STAIGER, E. Conceitos fundamentais da poética. 3. ed. Rio de Janeiro: Tempo Brasileiro, 1997.

Artigo recebido em 8 de Fevereiro de 2012 e aprovado em 19 de Abril de 2012 